\title{
Panel Granger Causality between oil consumption and GDP: \\ Evidence from BRICS countries*
}

\author{
Tsangyao Chang \\ (tychang@fcu.edu.tw) \\ (Department of Finance, Feng Chia University, Taichung, Taiwan)
}

Olorato Gadinabokao

(golorato@gmail.com)

(Department of Economics, University of Pretoria)

\author{
Rangan Gupta \\ (rangan.gupta@up.ac.za) \\ (Department of Economics, University of Pretoria)
}

Roula Inglesi-Lotz

(roula.inglesi-lotz@up.ac.za)

(Department of Economics, University of Pretoria)

\section{Pervan Kanniah}

(pervankanniah@yahoo.com)

(Department of Economics, University of Pretoria)

\author{
Beatrice D. Simo-Kengne \\ (beatrice.simo_kengne@up.ac.za) \\ (Department of Economics, University of Pretoria)
}

\footnotetext{
${ }^{*}$ We would like to thank three anonymous referees for many helpful comments. However, any remaining errors are solely ours.
} 


\begin{abstract}
This paper examines the causal relationship between oil consumption and economic growth in the BRICS countries for the period from 1985 to 2011. We employ a panel causality approach which accounts for both cross-sectional dependency and heterogeneity across countries. The empirical results support the view that oil consumption and economic growth are not sensitive to each other for the panel of BRICS countries. Looking at the individual country results, there is only some evidence for China of a bidirectional causality. The lack of sensitivity between oil consumption and GDP for the BRICS countries indicates that policies aiming at reducing the use of crude oil will have minor to no effect on the economic growth and development of the BRICS countries.
\end{abstract}

Keywords: Economic Growth; Dependency and Heterogeneity; Oil Consumption; BRICS; Panel Causality Test

\title{
1. Introduction
}

The fact that current modern economies are all in some degree dependent on energy is without dispute. Energy enhances not only the standard of living in a country but more importantly its production capability. It is argued that energy should be considered among the traditional factors of production such as capital and labour but also its importance in the improvement of their productivity should not be underestimated.

The significance of energy use is even more crucial for emerging economies such as the BRICS (Brazil, Russia, India, China and South Africa). The five countries, although in one collective group with similar characteristics and policy approaches, differ in terms of their level of development, distribution of wealth and relative states of human capital. Being contributors of approximately a quarter of the world's GDP, they primarily rely on traditional energy sources (coal, natural gas and oil) although their energy profiles differ due to dissimilar energy policies, resources, needs and investment decisions. 
Looking at data from the BP Statistical Review of World Energy 2013 (BP 2013), BRICS countries do possess a considerable fraction of the world's energy resources especially in coal (Crude Oil 7.75\%, Natural Gas 20.10\& \& Coal 42.61\%). BRICS countries consume $22.07 \%$ crude oil, $19.27 \%$ natural gas and $61.42 \%$ coal of the world's available energy resources; not a surprising fact taking into account that two of the highest in population countries in the world belong in the group (China and India) (BP 2013).

Although the BRICS countries are not the main producers of crude oil in the world, they consume more than one fifth of the world total crude oil consumption. Crude oil is considered a source of energy that finds application in most day-to-day functions from transporting workers to ensuring that production facilities operate at optimum levels. Hence, the importance of crude oil consumption particularly for emerging economies is indisputable.

The question here however would be whether crude oil consumption is an input to production or the higher levels of growth will lead to rising oil consumption. Figure 1 presents the average crude oil consumption and average GDP for the BRICS countries, confirming that both variables have shown an increasing trend through the years, almost identical to each other.

Figure 1: Average crude oil consumption and average GDP for the BRICS countries

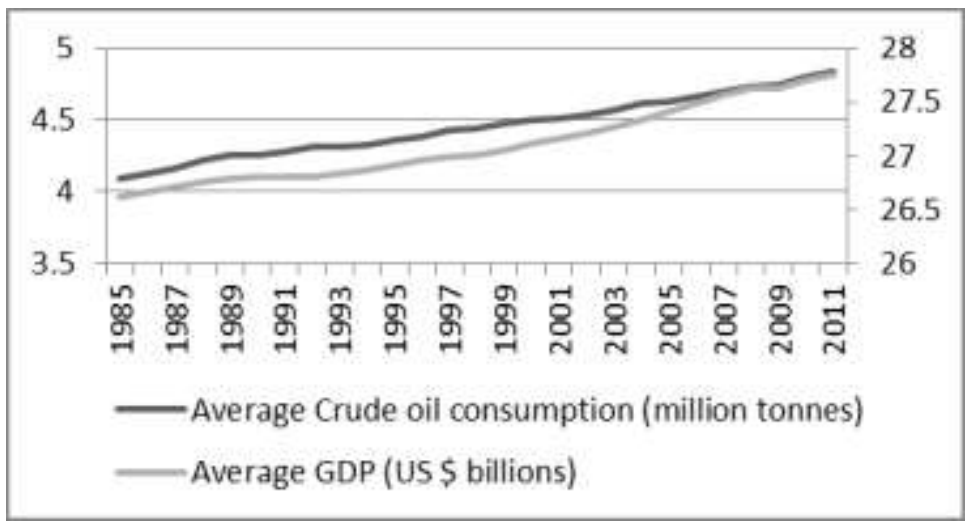

Source: BP (2013) and World Bank (2013) 
Research on the causal relationship between energy and GDP growth has attracted increasing attention recently with primary focus, however, on a basket of energy commodities namely oil, coal and gas. The body of literature evaluating specifically the crude oil consumption and economic growth relationship is more limited. In the case of Turkey a bi-directional causal relation exists between oil consumption and economic growth according to Aktas and Yilmaz (2008). In this research, oil was cited as being a critical factor in ensuring the economic wellbeing of Turkey. In the case of Nepal a bi-directional relationship was found between oil consumption and economic growth in the short and long run, Bhusal (2010). Oil was again cited as being a critical factor of production in sustaining production in manufacturing industry, transportation and electricity generation. Yoo (2006) demonstrates that there exists again a bi-directional causality between oil consumption and GDP growth for Korea. According to Yoo (2006) Korea is new to industrialisation and as result oil consumption plays an integral role in economic growth.

Investigating causality between energy consumption (oil consumption when applicable) and GDP did provide some insight into the nature of causality, however no consensus was reached. A number of individual-country analyses have been conducted looking at the interesting case of the BRICS countries. Research by Zou and Chau (2005) found that consumption of oil has kept pace with the China's rapidly growing economy even though the country primary source of energy is coal. The research also found that oil consumption has an influential impact on the Chinese economy. Russia has the largest energy reserves amongst the BRICS countries and according to Apergis and Payne (2010) bi-directional casualty between energy consumption and growth exists both in the long and short-run when conducting multivariate panel data analysis for Eurasia. Cheng (1996) established that there is a link between energy consumption and economic growth for Brazil when using a panel Granger causality framework. Paul and Bhattacharya (2004) found that bi-directional 
causality exists between energy consumption and economic growth for India. Wolde-Rufael (2006) found in a study of 17 African countries including South Africa that a causal relationship between electricity consumption and economic growth does exist.

The purpose of this paper is to determine the existence and direction of a causal relationship between oil consumption and GDP for the panel of BRICS economies. This paper uses the bootstrap panel granger causality approach as specified in Emirmahmutoglu and Kose (2011) to do so over the period 1985 to 2011 . This method has two main advantages: it takes into account possible cross-sectional dependency and slope heterogeneity. Considering the latter ensures that the econometric approach acknowledges the geopolitical and socioeconomic differences among the BRICS countries. The issue of dependency among them stems from the current dynamics of an interlinked, interdependent world economy: the impact of a shock in one country might be effectively transmitted to more countries. Both these issues should be tested and are essential in capturing the reality of the BRICS countries.

The paper is structured as follows. The next section presents a brief literature review while section 3 explains in detail the methodological approach and data used. The subsequent section presents the empirical results of the analysis while the last section concludes and provides the results' policy implications.

\section{Methods}

In the current interconnected and open world economy, panel causality analysis ought to take into consideration two important issues: slope heterogeneity and cross-section dependency. Thus, before explaining the causality test, the issues of cross-sectional dependency and heterogeneity of slope coefficients are tested. In what follows, we outline the essentials of the econometric methods used in this study. 


\subsection{Testing cross-sectional dependency}

To test for cross-sectional dependency, the Lagrange multiplier (LM hereafter) test of Breusch and Pagan (1980) has been extensively used in empirical studies. The procedure to compute the LM test.

Under the null hypothesis of cross-sectional independence, the $L M$ statistic has asymptotic chi-square with $N(N-1) / 2$ degrees of freedom. It is important to note that the $L M$ test is valid for $N$ relatively small and $T$ sufficiently large.

However, the cross dependence (CD) test is subject to decreasing power in certain situations where the population average pair-wise correlations are zero, although the underlying individual population pair-wise correlations are non-zero (Breusch and Pagan, 1980). Furthermore, in stationary dynamic panel data models the CD test fails to reject the null hypothesis when the factor loadings have zero mean in the cross-sectional dimension. In order to deal with these problems, Pesaran et al. (2008) propose a bias-adjusted test which is a modified version of the $L M$ test by using the exact mean and variance of the $L M$ statistic.

Under the null hypothesis with first $T \rightarrow \infty$ and then $N \rightarrow \infty, L M_{a d j}$ test is asymptotically distributed as standard normal. The readers are referred to the papers by Breusch and Pagan (1980) and Pesaran et al., (2008) for further details.

\subsection{Testing slope homogeneity}

The second issue investigated here is to test whether or not the slope coefficients are homogenous. The causality from one variable to another variable by imposing the joint restriction for the whole panel is the strong null hypothesis (Granger 2003). Moreover, the homogeneity assumption for the parameters is not able to capture heterogeneity due to region specific characteristics (Breitung, 2005).

The most familiar way to test the null hypothesis of slope homogeneity- $H_{0}: \beta_{i}=\beta$ for all $i$ against the hypothesis of heterogeneity- $H_{1}: \beta_{i} \neq \beta_{j}$ for a non-zero fraction of pair-wise slopes 
for $i \neq j$ - is to apply the standard $F$ test. The $F$ test is valid for cases where the cross section dimension $(N)$ is relatively small and the time dimension $(T)$ of panel is large; the explanatory variables are strictly exogenous; and the error variances are homoscedastic. By relaxing homoscedasticity assumption in the $F$ test, Swamy (1970) developed the slope homogeneity test on the dispersion of individual slope estimates from a suitable pooled estimator. However, both the $F$ and Swamy's test require panel data models where $N$ is small relative to T. Pesaran and Yamagata (2008) proposed a standardized version of Swamy's test (the socalled $\tilde{\Delta}$ test) for testing slope homogeneity in large panels. The $\tilde{\Delta}$ test is valid as $(N, T) \rightarrow \infty$ without any restrictions on the relative expansion rates of $\mathrm{N}$ and $\mathrm{T}$ when the error terms are normally distributed.

Under the null hypothesis with the condition of $(N, T) \rightarrow \infty$ so long as $\sqrt{N} / T \rightarrow \infty$ and the error terms are normally distributed, the $\tilde{\Delta}$ test has asymptotic standard normal distribution. The small sample properties of $\tilde{\Delta}$ test can be improved under the normally distributed errors by using a bias-adjusted version $\tilde{\Delta}_{a d j}$ :

The presence of cross-sectional dependence and heterogeneity over the sample period implies that the panel causality test that imposes the homogeneity restriction and does not account for spillover effects across units may result in misleading inferences; hence providing the rationale of using the bootstrap panel causality approach.

\subsection{Panel Granger Causality analysis}

Emirmahmutoglu and Kose (2011) propose a causality test in heterogeneous mixed panels based on the meta analysis of Fisher (1932). They extended the Lag Augmented VAR (LAVAR) approach by Toda and Yamamoto (1995), which uses the level VAR model with extra dmax lags to test Granger causality between variables in heterogeneous mixed panels. Consider a level VAR model with $k_{i}+d \max _{i}$ lags in heterogeneous mixed panels: 


$$
\begin{aligned}
& x_{i, t}=\mu_{i}^{x}+\sum_{j=1}^{k_{i}+d \max _{i}} A_{1, i j} x_{i, t-j}+\sum_{j=1}^{k_{i}+d \max _{i}} A_{12, i j} y_{i, t-j}+\mu_{i, t}^{x} \\
& y_{i, t}=\mu_{i}^{y}+\sum_{j=1}^{k_{i}+d \max _{i}} A_{21, i j} x_{i, t-j}+\sum_{j=1}^{k_{i}+d \max _{i}} A_{22, i j} y_{i, t-j}+\mu_{i, t}^{y}
\end{aligned}
$$

where $i(i=1, \ldots \ldots N)$ denotes individual cross-sectional units and $t(t=1, \ldots \ldots$.$) denotes$ time periods, $\mu_{i}^{x}$ and $\mu_{i}^{y}$ are two vectors of fixed effects, $\mu_{i, t}^{x}, \mu_{i, t}^{y}$, are column vectors of error terms, $k_{i}$ is the lag structure which is assumed to be known and may differ across crosssectional units, and $\operatorname{dmax}_{i}$ is the maximal order of integration in the system for each $i$. Following the bootstrap procedure by Emirmahmutoglu and Kose (2011), testing causality from $x$ to $y$ is summarized as follows:

I. Determine the maximal order $d \max _{i}$ of integration of variables in the system for each cross-section unit based on the Augumented Dickey Fuller (ADF) unit root test and select the lag orders $k_{i}$ via information criteria (AIC or SB) by estimating the regressions (2) using the OLS method.

II. Re-estimate equation (2) using the $\operatorname{dmax}_{i}$ and $k_{i}$ under the non-causality hypothesis and attain the residuals for each individual.

$$
\hat{u}_{i, t}^{y}=y_{i, t}-\hat{u}_{i}^{y}+\sum_{j=1}^{k_{i}+d \max _{i}} \hat{A}_{21, i j} x_{i, t-j}+\sum_{j=1}^{k_{i}+d \max x_{i}} \hat{A}_{22, i j} y_{i, t-j}
$$

III. Residuals are centred using Stine's (1987) suggestion, i.e.,

$$
\tilde{u}_{t}=\hat{u}_{t}-(T-k-l-2)^{-1} \sum_{t=k+l+2}^{T} \hat{u}_{t}
$$

where $\hat{\mu}_{t}=\left(\hat{\mu}_{1 t}, \hat{\mu}_{2 t}, \ldots \ldots, \hat{\mu}_{N t}\right)^{\prime}, k=\max \left(k_{i}\right)$ and $l=\max \left(d \max _{i}\right)$. Next, we develop the $\left[\tilde{\mu}_{i . t}\right]_{N \times T}$ from these residuals. We select randomly a full column with replacement from the matrix at a time to preserve the cross covariance structure of the errors. We denote the bootstrap residuals as $\tilde{\mu}_{t}^{*}$ where $t=(1, \ldots . T)$. 
IV. A bootstrap sample of y is generated under the null hypothesis, i.e.

$y_{i, t}^{*}=\hat{\mu}_{i}^{y}+\sum_{j=1}^{k_{i}+d \max _{i}} \hat{A}_{21, i j} x_{i, t-j}+\sum_{j=1}^{k_{i}+d \max _{i}} \hat{A}_{22, i j} y_{i, t-j}^{*}+u_{i, t}^{*}$

where $\hat{\mu}_{i}^{y} \hat{A}_{12, i j}$ and $\hat{A}_{22, i j}$ are the estimations from step 3 .

V. For each individual, Wald statistics are calculated to test for the non-causality null hypothesis by substituting $y_{i, t}^{*}$ for $y_{i, t}$ and estimating equation (2) without imposing any parameter restrictions.

VI. Using individual p-values $\left(p_{i}\right)$ that correspond to the Wald statistic of the ith individual cross-section, the Fisher test statistic $\lambda$ is obtained as follows:

$$
\lambda=-2 \sum_{i=1}^{N} \ln \left(p_{i}\right) \quad \mathrm{i}=1, \ldots \ldots, \mathrm{N}
$$

VII. The bootstrap empirical distribution of the Fisher test statistics are generated by repeating steps 3 to 510,000 times and specifying the bootstrap critical values by selecting the appropriate percentiles of these sampling distributions.

Using simulation studies, Emirmahmutoglu and Kose (2011) demonstrate that the performance of LA-VAR approach under both the cross-section independency and dependency is satisfactory for the entire values of $\mathrm{T}$ and $\mathrm{N}$.

\subsection{Data}

To conduct the analysis, we obtain data on real GDP per capita from World Development Indicators of the World Bank (World Bank, 2013) measured in US \$ billion and crude oil consumption data from the BP Statistical Review of World Energy 2013 (BP 2013) measured in thousand barrels. Both series are used in their natural logs. 


\section{Results}

In order to investigate the integrated properties of the series for all countries, we use the Augmented Dickey Fuller (1979) (ADF) test, as in Emirmahmutoglu and Kose (2011). The results on the levels, first differences and second differences with their p-values are recorded in Table 2. The results show that at a 5\% level of significance that the null hypothesis of a unit root for both GDP and oil consumption is rejected in the levels and first differences for 4 of the countries except India. For Brazil, India, China and Russia both variables are integrated of order 2 i.e. are $I(2)$ series whereas India is integrated of order $1 .^{1}$

To investigate the existence of cross sectional dependency, we performed four different tests including $C D_{B P}, C D_{L M}, C D, L M_{a d j}$. The results are reported in Table 1.

Table 1. Cross-sectional Dependence and Homogenous Test

\begin{tabular}{ll}
\hline$C D_{B P}$ & $27.375^{* * *}$ \\
$C D_{L M}$ & $3.885^{* * *}$ \\
$C D$ & $3.295^{* * *}$ \\
$L M_{a d j}$ & $58.803^{* * *}$ \\
$\tilde{\Delta}$ & 0.5810 \\
$\tilde{\Delta}_{a d j}$ & 0.0182 \\
Swamy Shat & $53.0497^{* * *}$ \\
\hline
\end{tabular}

Note: $1 . * * *, * *$, and $*$ indicate significance at the $0.01,0.05$, and 0.1 levels, respectively.

It is evident from the results that the null hypothesis of no cross-sectional dependency is strongly rejected in favor of the alternative of cross-sectional dependency at a $1 \%$ level of significance, meaning that a shock originating in one country may spill over onto other countries. This should be taken into account when examining the causal links between natural gas consumption and economic growth.

\footnotetext{
${ }^{1}$ The results of the test are available from the authors upon request.
} 
Though $\tilde{\Delta}$ and $\tilde{\Delta}_{a d j}$ fail to reject the null hypothesis of slope homogeneity in favor of the alternative hypothesis of no homogeneity, Swamy Shat strongly rejects the null hypothesis of slope homogeneity, this implies that the panel causality analysis by imposing homogeneity restriction on the variable of interest may result in misleading inferences. Therefore country specific characteristics should be taken into account.

Confirming the existence of cross sectional dependency and heterogeneity across the five countries, thereby implies the appropriateness of the bootstrap causality approach. The bootstrap causality results are generated from the VAR model with $k_{i}+d \max _{i}$ lags. The bootstrap empirical distribution of the Fisher test statistic is determined by repeating steps 3-5 many times and then specifying the bootstrap critical values by selecting the percentiles of the sampling distribution. Results for the bootstrap causality approach are presented in Table 2.

Table 2: Causality analysis

\begin{tabular}{|c|c|c|c|c|c|c|c|}
\hline \multicolumn{8}{|c|}{ GDP does not Granger cause Crude oil Consumption } \\
\hline & \multicolumn{3}{|c|}{ Schwartz-Bayesian Criterion } & & \multicolumn{3}{|c|}{ Akaike Information Criterion } \\
\hline Country & Lag length & $\begin{array}{c}\text { Wald } \\
\text { Statistics }\end{array}$ & p-value & & Lag length & $\begin{array}{c}\text { Wald } \\
\text { Statistics }\end{array}$ & p-value \\
\hline Brazil & 1 & 0 & 0.991 & & 1 & 0 & 0.991 \\
\hline Russia & 1 & 1.699 & 0.192 & & 2 & 2.011 & 0.366 \\
\hline India & 1 & 0.153 & 0.696 & & 1 & 0.153 & 0.696 \\
\hline China & 1 & $6.070 * *$ & 0.014 & & 3 & 4.8 & 0.187 \\
\hline South Africa & 3 & 2.203 & 0.531 & & 3 & 2.203 & 0.531 \\
\hline Fisher test value & \multicolumn{3}{|c|}{ Bootstrap Critical value } & $\begin{array}{c}\text { Fisher test } \\
\text { value }\end{array}$ & \multicolumn{3}{|c|}{ Bootstrap Critical value } \\
\hline \multirow[t]{2}{*}{13.879} & $10 \%$ & $5 \%$ & $1 \%$ & 7.373 & $10 \%$ & $5 \%$ & $1 \%$ \\
\hline & 18.834 & 22.454 & 30.97 & & 20.677 & 24.479 & 35.568 \\
\hline & & & & & & & \\
\hline \multicolumn{8}{|c|}{ Crude oil consumption does not Granger cause GDP } \\
\hline & \multicolumn{3}{|c|}{ Schwartz-Bayesian Criterion } & & \multicolumn{3}{|c|}{ Akaike Information Criterion } \\
\hline Country & Lag length & $\begin{array}{c}\text { Wald } \\
\text { Statistics }\end{array}$ & p-value & & Lag length & $\begin{array}{c}\text { Wald } \\
\text { Statistics }\end{array}$ & p-value \\
\hline
\end{tabular}




\begin{tabular}{|c|c|c|c|c|c|c|c|}
\hline Brazil & 1 & 0.042 & $\begin{array}{l}0.838 \\
\end{array}$ & & 1 & 0.042 & 0.838 \\
\hline Russia & 1 & 0.165 & 0.685 & & 2 & 1.229 & 0.541 \\
\hline India & 1 & 0.687 & 0.407 & & 1 & 0.687 & 0.407 \\
\hline China & 1 & 0.001 & 0.975 & & 3 & $12.064 * * *$ & 0.007 \\
\hline South Africa & 3 & 6.159 & 0.104 & & 3 & 6.159 & 0.104 \\
\hline Fisher test value & \multicolumn{3}{|c|}{ Bootstrap Critical value } & $\begin{array}{c}\text { Fisher test } \\
\text { value }\end{array}$ & \multicolumn{3}{|c|}{ Bootstrap Critical value } \\
\hline 7.484 & $10 \%$ & $5 \%$ & $1 \%$ & 17.781 & $10 \%$ & $5 \%$ & $1 \%$ \\
\hline & 18.816 & 22.073 & 29.413 & & 21.03 & 24.767 & 34.414 \\
\hline
\end{tabular}

The overall results for the panel of BRICS countries suggest that the null of no Granger causality from economic growth to crude oil consumption and vice versa cannot be rejected (Fisher-test values smaller than the Bootstrap critical values). This result indicates that for the overall panel the neutrality hypothesis is confirmed.

Moreover individual country results confirm the panel results with the exception of China where, when using the Akaike Information Criterion, there is evidence for causality running from GDP to crude oil consumption (Wald statistic shows that the null hypothesis that the GDP does not Granger cause crude oil consumption can be rejected at 5\% level of significance) while the opposite direction holds when using the Schwartz criterion (Wald statistic shows that the null hypothesis that the crude oil consumption does not Granger cause GDP can be rejected at $1 \%$ level of significance). Hence for China a bidirectional causal relationship between crude oil consumption and GDP can be confirmed. ${ }^{2}$

\footnotetext{
${ }^{2}$ As suggested by one of the referees, we also employed more powerful unit root tests like the Phillips and Perron (1988), Kwiatkowski et al., (KPSS, 1992), Elliot et al., (ERS, 1996), Ng and Perron (2001). In general, the results were quite mixed, and did not necessarily refute the findings of the ADF test. We, however, redid the causality tests using $\operatorname{dmax}_{i}=1$ for all cases. We found that again, for the whole panel, the results reported in Table 2 continues to hold, i.e., there is no causality in either direction for the entire panel. The exception is South Africa, which now shows bi-directional causality instead of China, when lag-lengths are chosen based on the SIC. There is also evidence of uni-directional causality from crude oil to GDP at the 10 percent level for South Africa. This is similar to results we already have in Table 2 to certain extent, since causality from oil to GDP was seen with a $p$-value of 0.104 for South Africa, under both the AIC and SIC. However, given that we are considering effects on growth, we believe that it is better to use longer lags based on the higher values of $d \max _{i}$ and also the $A I C$ to accommodate for delayed dynamics, which in turn implies that more reliability should be placed on the results reported in Table 2. The details of these results are available upon request from the authors. As part of future research, it would be interesting to use the frequency-domain based causality test of Breitung and Candelon (2006), which would allow us to decompose causality at various frequencies and hence
} 


\section{Conclusion and Policy Implications}

The purpose of this research was to determine the existence and direction of the causal relationship between oil consumption and real GDP per capita for the panel of BRICS economies. This paper uses the bootstrap panel Granger causality approach as specified in Emirmahmutoglu and Kose (2011) to test a causal link between oil consumption and GDP for the BRICS group of countries from 1985 to 2011.

Our findings show that there is no causal relationship between oil consumption and real GDP per capita for the overall panel of BRICS countries. Looking at the countries individually, only for China we confirm evidence for a bidirectional causality.

This lack of a causal relationship might be explained by the traditional and continuous consumption of crude oil in these countries. Increases or decreases in crude oil do not have an impact to the countries' economic growth because there may be other substitutes incorporated in the system. Also, most of the BRICS countries use coal-generated electricity in their production processes and hence, they do not get affected by changes in the crude oil reserves. Finally, these results are encouraging for future policies that aim to reduce the use of crude oil in favour of cleaner alternatives will not bear negative consequences to the BRICS economies.

The case of China is the only exception in this "rule". The causal linkages between oil consumption and GDP for China is not surprising even though the primary source of energy for China is coal according to Zou and Chau (2005), who also found that China's oil consumption has kept pace with its growing economy. Hence, the announcement (Oil Patch Asia, 2014) of "China National Petroleum Corporation" (CNPC) Chairman in the beginning of 2014 of their plans to seek joint investment with the private sector to extend the oil

\footnotetext{
identify short- and long run causalities, if any. However, it must be realized that this test is a time-series based approach and hence cannot account for cross-sectional dependence, which as we show is present significantly amongst the BRICS.
} 
infrastructure of the country might lead to further increase oil consumption and improve economic growth.

\section{References}

Aktas, C and Yilmaz, V. 2008. Causal Relationship Between Oil Consumption And Economic Growth In Turkey. Kocaeli Üniversitesi Sosyal Bilimler Enstitüsü Dergisi 15(1), 45-55.

Apergis, N., and Payne, J.E. 2010. Renewable energy consumption and growth in Eurasia. Energy economics 32, $1392-1397$.

Bhusal, T.P. 2010. Econometric Analysis of Oil Consumption and Economic Growth in Nepal. Economic Journal of Development Issues 11 \&12, 135-143.

BP. 2013. Statistical Review of World Energy 2013. http://www.bp.com/en/global/corporate/about-bp/statistical-review-of-world-energy2013.html

Breitung, J. 2005. A parametric approach to the estimation of cointegration vectors in panel data. Econometric Reviews 24, 151-173.

Breitung, J. and Candelon, B. (2006).Testing for short- and long-run causality: A frequencydomain approach. Journal of Econometrics 132, 363-378.

Breusch, T. S., and Pagan, A. R. 1980. The Lagrange Multiplier test and its applications to model specification in econometrics. The Review of Economic Studies 47, 239-253.

Cheng, B.S. 1996 Energy consumption and economic growth in Brazil, Mexico and Venezuela: A time series analysis, Applied Economics Letters 4 671-674.

Dickey, D.A. and W.A. Fuller, 1979, Distribution of the estimators for autoregressive time series with a unit root, Journal of the American Statistical Association 74, 355-367. 
Elliot, G., Rothenberg, T.J. and Stock, J.H. 1996. Efficient tests for an autoregressive unit root. Econometrica, 64, 813-836.

Emirmahmutoglu, F. and Kose, N., 2011. Testing for Granger causality in heterogeneous mixed panels, Economic Modelling, 28, 870-876.

Fisher, R.A., 1932. Statistical Methods for Research Workers, 4th edition. Oliver and Boyd, Edinburgh.

Granger, C.W.J. 2003. Some aspects of causal relationships. Journal of Econometrics 112, $69-71$.

Kwiatkowski, D., Phillips, P.C.B., Schmidt, P., Shin, Y. (1992). Testing the null hypothesis of stationarity against the alternative of a unit root. Journal of Econometrics, 54, 159-178. Narayan P.K., Smyth R., 2008. Energy consumption and real GDP in G7 countries: New evidence from panel cointegration with structural breaks. Energy Economics 30, 2331-2341. Ng, S. and Perron, P. (2001). Lag length selection and the construction of unit root tests with good size and power. Econometrica, 69, 1519-54.

Oil Patch Asia. 2014. CNPC Chairman starts courting private investors. Available at : http://oilpatchasia.com/2014/03/cnpc-chairman-starts-courting-private-investors/ Paul, S., and . Bhattacharya, R.N. 2004. Causality between energy consumption and economic growth in India: a note on conflicting results. Energy Economics 26, 977-983

Pesaran, M. H. and Yamagata, T. 2008. Testing slope homogeneity in large panels. Journal of Econometrics 142, 50-93.

Pesaran, M. H., Ullah, A. and Yamagata, T. 2008. A bias-adjusted LM test of error crosssection independence. Econometrics Journal 11, 105-127.

Phillips, P.C.B. and Perron, P. (1988).Testing for a unit root in time series regression, Biometrika 75, 335-346 
Stine, R.A., 1987. Estimating properties of autoregressive forecasts. Journal of the American Statistical association 82, 1072-1078.

Swamy, P.A.V.B. 1970. Efficient inference in a random coefficient regression model. Econometrica 38, 311-323.

Toda, H.Y., Yamamoto, T., 1995. Statistical inference in vector autoregressions with possibly integrated processes. Journal of Econometrics 66, 225-250.

Wolde-Rufael, Y. 2006. Electricity consumption and economic growth: a time series experience for 17 African countries. Energy Policy 34 1106-1114

World Bank. 2013. World Development Indicators (WDI). Washington, US.

Yoo, S., H. 2006, Oil Consumption and Economic Growth: Evidence from Korea. Economics, Planning, and Policy 1, 235-243.

Zou, G., and Chau, K,W. 2005. Short- and long-run effects between oil consumption and economic growth in China. Energy Policy 34, 3644-3655 
Figure 1: Average crude oil consumption and average GDP for the BRICS countries

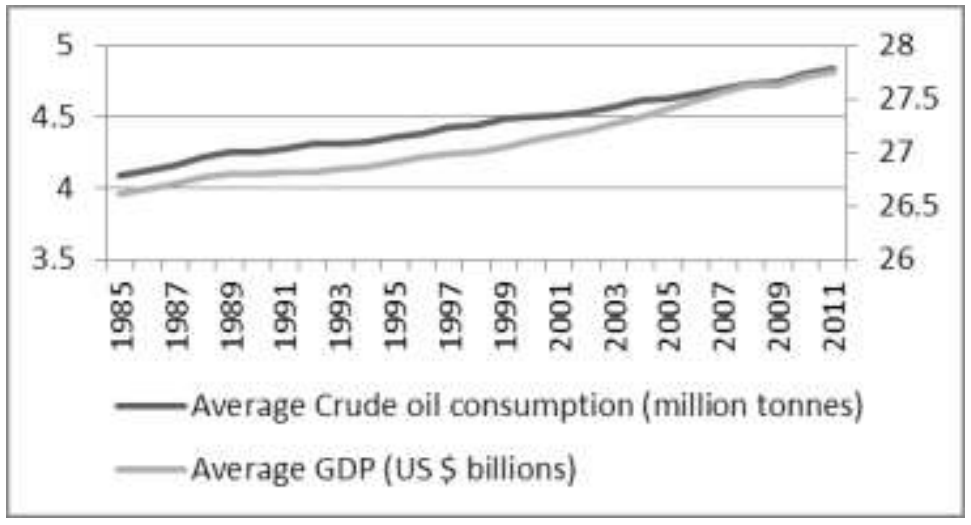

Source: BP (2013) and World Bank (2013)

Table 2: Causality analysis

\begin{tabular}{|c|c|c|c|c|c|c|c|}
\hline \multicolumn{8}{|c|}{ GDP does not Granger cause Crude oil Consumption } \\
\hline & \multicolumn{3}{|c|}{ Schwartz-Bayesian Criterion } & & \multicolumn{3}{|c|}{ Akaike Information Criterion } \\
\hline Country & $\begin{array}{c}\text { Lag } \\
\text { length }\end{array}$ & $\begin{array}{c}\text { Wald } \\
\text { Statistics }\end{array}$ & p-value & & $\begin{array}{c}\text { Lag } \\
\text { length }\end{array}$ & $\begin{array}{c}\text { Wald } \\
\text { Statistics }\end{array}$ & $\begin{array}{c}p- \\
\text { value }\end{array}$ \\
\hline Brazil & 1 & 0 & 0.991 & & 1 & 0 & 0.991 \\
\hline Russia & 1 & 1.699 & 0.192 & & 2 & 2.011 & 0.366 \\
\hline India & 1 & 0.153 & 0.696 & & 1 & 0.153 & 0.696 \\
\hline China & 1 & $6.070 * *$ & 0.014 & & 3 & 4.8 & 0.187 \\
\hline South Africa & 3 & 2.203 & 0.531 & & 3 & 2.203 & 0.531 \\
\hline $\begin{array}{l}\text { Fisher test } \\
\text { value }\end{array}$ & \multicolumn{3}{|c|}{ Bootstrap Critical value } & $\begin{array}{c}\text { Fisher } \\
\text { test value }\end{array}$ & \multicolumn{3}{|c|}{ Bootstrap Critical value } \\
\hline \multirow[t]{2}{*}{13.879} & $10 \%$ & $5 \%$ & $1 \%$ & 7.373 & $10 \%$ & $5 \%$ & $1 \%$ \\
\hline & 18.834 & 22.454 & 30.97 & & 20.677 & 24.479 & 35.568 \\
\hline & & & & & & & \\
\hline \multicolumn{8}{|c|}{ Crude oil consumption does not Granger cause GDP } \\
\hline & \multicolumn{3}{|c|}{ Schwartz-Bayesian Criterion } & & \multicolumn{3}{|c|}{ Akaike Information Criterion } \\
\hline Country & $\begin{array}{c}\text { Lag } \\
\text { length }\end{array}$ & $\begin{array}{c}\text { Wald } \\
\text { Statistics }\end{array}$ & p-value & & $\begin{array}{c}\text { Lag } \\
\text { length }\end{array}$ & $\begin{array}{c}\text { Wald } \\
\text { Statistics }\end{array}$ & $\begin{array}{c}p- \\
\text { value }\end{array}$ \\
\hline Brazil & 1 & 0.042 & 0.838 & & 1 & 0.042 & 0.838 \\
\hline Russia & 1 & 0.165 & 0.685 & & 2 & 1.229 & 0.541 \\
\hline India & 1 & 0.687 & 0.407 & & 1 & 0.687 & 0.407 \\
\hline
\end{tabular}




\begin{tabular}{|c|c|c|c|c|c|c|c|}
\hline China & 1 & 0.001 & 0.975 & & 3 & $12.064 * * *$ & 0.007 \\
\hline South Africa & 3 & 6.159 & 0.104 & & 3 & 6.159 & 0.104 \\
\hline $\begin{array}{l}\text { Fisher test } \\
\text { value }\end{array}$ & \multicolumn{3}{|c|}{ Bootstrap Critical value } & $\begin{array}{c}\text { Fisher } \\
\text { test value }\end{array}$ & \multicolumn{3}{|c|}{ Bootstrap Critical value } \\
\hline 7.484 & $10 \%$ & $5 \%$ & $1 \%$ & 17.781 & $10 \%$ & $5 \%$ & $1 \%$ \\
\hline & 18.816 & 22.073 & 29.413 & & 21.03 & 24.767 & 34.414 \\
\hline
\end{tabular}

